\title{
A case of mitochondrial cardiomyopathy with restrictive transmitral filling pattern
}

This article was published in the following Dove Press journal:

International Medical Case Reports Journal

II April 2012

Number of times this article has been viewed

\section{Kazunori Otsui \\ Nobutaka Inoue \\ Anna Tamagawa \\ Kazuo Onishi}

Department of Cardiovascular Medicine, Kobe Rosai Hospital, Kobe, Japan
Correspondence: Nobutaka Inoue Department of Cardiovascular Medicine, Kobe Rosai Hospital, 4-I-23, Kagoike Touri, Chuo-Ku, Kobe 65I-0053, Japan $\mathrm{Tel}+817823$ I 5901

Fax +8I 782425316

Email nobutaka@kobeh.rofuku.go.jp

\begin{abstract}
A 61-year-old diabetic woman with a mitochondrial A3243G mutation was hospitalized for evaluation of breathlessness, general fatigue, and leg edema. Chest radiography revealed cardiomegaly with massive pleural effusion. Serum lactate, pyruvate, and brain natriuretic peptide concentrations were elevated. Transthoracic echocardiography revealed a restrictive pattern of transmitral flow, although systolic function of the left ventricle was only mildly impaired. Based on these findings and her clinical course, the patient was diagnosed with right-sided heart failure caused by mitochondrial cardiomyopathy associated with a restrictive transmitral filling pattern. Treatment with furosemide, enalapril, and eplerenone was effective, and improvement in her symptoms was associated with amelioration of transthoracic echocardiographic findings and a reduction in serum brain natriuretic peptide levels. Previous reports have indicated heterogeneity in the clinical features of mitochondrial cardiomyopathy in patients carrying the $\mathrm{A} 3243 \mathrm{G}$ mutation; the present case highlights the substantial variability in the clinical features of this disease.
\end{abstract}

Keywords: mitochondrial disease, A3243G mutation, diastolic dysfunction, transmitral flow

\section{Introduction}

Mitochondrial diseases are heterogeneous disorders that result from the genetic derangement of mitochondrial DNA with associated alterations in mitochondrial structure and biochemical properties. Although mitochondrial diseases are usually characterized by encephalomyopathy, multiorgan systems can also be involved. The acronym "MELAS" (mitochondrial encephalomyopathy, lactic acidosis, and stroke-like episodes) describes the classic clinical phenotype of the mitochondrial syndromes. ${ }^{1}$ The heart, which is highly dependent on energy produced by mitochondrial oxidation, is vulnerable to the effects of mitochondrial DNA mutation. However, it has been reported that patients with mitochondrial cardiomyopathy showed a wide variety of clinical presentations. Here we describe the case of a Japanese woman who was diagnosed with a mitochondrial A3243G mutation, and presented with right-sided heart failure and a restrictive pattern of transmitral flow.

\section{Case report}

A 61-year-old female was admitted after complaining of breathlessness and leg edema. She had been diagnosed with diabetes when she was 27 years of age, and insulin therapy was started at the age of 55 years. The patient had severe sensorineural hearing impairment, but showed normal mental activity. Because of the coexistence of sensorineural hearing impairment and diabetes, a mitochondrial disorder was suspected. 


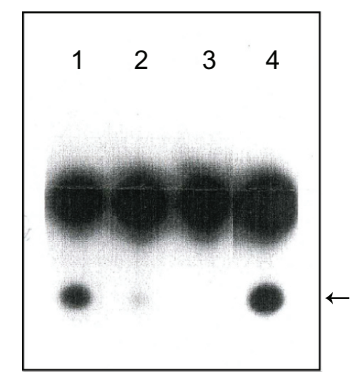

Figure I Restriction enzyme analysis of mitochondrial DNA.

Notes: The polymerase chain reaction products of mitochondrial DNA isolated from peripheral leukocytes were digested overnight with Apa-I, which cleaves the mutation sequence (GGGCCC) at position 3243 but not the wild-type sequence (GAGCCC). The 137 bp mutant fragment, but not of the wild-type fragment, was observed following digestion by a restriction enzyme Apa-I. Lane I, positive control containing $10 \%$ mutated DNA; lane 2, positive control containing $1 \%$ mutated DNA; lane 3 , negative control; lane 4 , the present case.

Therefore, analysis of mitochondrial DNA was performed at the age of 56 years, and demonstrated a mitochondrial DNA mutation involving $\mathrm{A} \rightarrow \mathrm{G}$ transition at nucleotide 3243 (A3243G) in the tRNA Leu (UUR) gene (Figure 1). For 3 weeks prior to hospitalization, she had been suffering from exertional breathlessness, general fatigue, and leg edema. Despite appetite loss, her weight had increased by $6.5 \mathrm{~kg}$, accompanied by gradually worsening of symptoms. On admission, blood pressure was $102 / 80 \mathrm{mmHg}$ and pulse rate was 80 beats per minute. Height and weight were $154 \mathrm{~cm}$ and $41.6 \mathrm{~kg}$, respectively. $\mathrm{SpO}_{2}$ was $96 \%$ on room air. The jugular vein was dilated, and a regurgitant systolic murmur and third sound at the apex were audible. The abdomen was soft and flat, and the liver was not palpable, but she showed substantial leg edema. There was no weakness in the limb muscles.
Chest radiography showed massive pleural effusion (Figure 2A). An electrocardiogram revealed sinus tachycardia and left ventricular hypertrophy with strain pattern (Figure 2B). The results of the laboratory investigations are shown in Table 1. Serum levels of lactate and pyruvate were elevated $(3.4 \mathrm{mmol} / 1$ and $1.37 \mathrm{mg} / \mathrm{dL}$, respectively), and the serum level of brain natriuretic peptide was markedly elevated to $1130 \mathrm{pg} / \mathrm{mL}$. Arterial blood gas analysis showed metabolic acidosis with elevation of lactate levels.

As shown in Figure 3, transthoracic echocardiography showed slight dilation of the left ventricle and left atrium, a left ventricular end-diastolic dimension of $53 \mathrm{~mm}$, and a left atrial dimension of $46 \mathrm{~mm}$. Wall motion of the left ventricle was mildly reduced, and the left ventricular ejection fraction was $45 \%$. Left ventricular hypertrophy was not observed, and ventricular septal thickness was $10 \mathrm{~mm}$. Pulsed wave Doppler imaging identified a restrictive transmitral filling pattern. The E/A value was 3.4, and deceleration time of E was significantly reduced to $125 \mathrm{msec}$. The inferior vena cava was markedly dilated. Coronary angiography did not reveal any significant stenosis.

Based on these findings and the patient's clinical course, we ascribed her symptoms to right-sided heart failure caused by mitochondrial cardiomyopathy with a restrictive transmitral filling pattern. The patient was treated with furosemide $40 \mathrm{mg}$ /day, enalapril $5 \mathrm{mg} /$ day, and eplerenone $50 \mathrm{mg} /$ day. The patient's clinical course is summarized in Figure 4. Symptoms were markedly improved following initiation of treatment. Her body weight decreased and the pleural effusion seen on chest radiography disappeared 15 days after admission. Improvement in her symptoms was associated
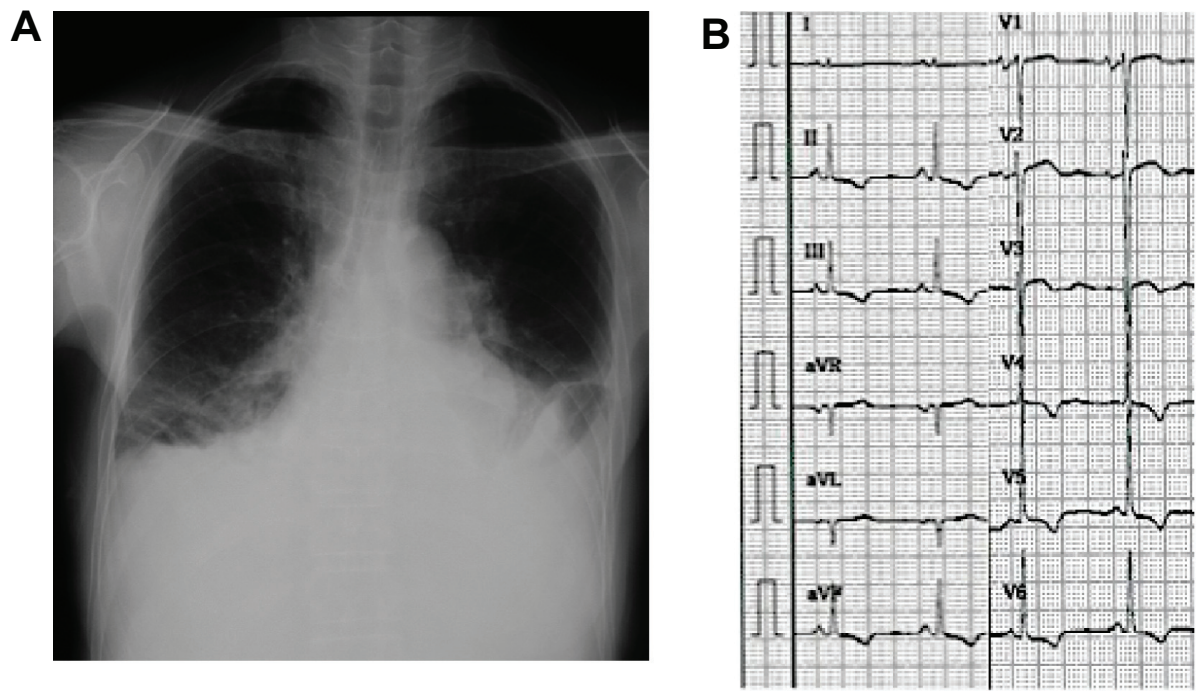

Figure 2 (A) Chest roentgenogram showing cardiomegaly with massive pleural effusion. (B) Electrocardiogram at admission. 
Table I Laboratory data at the admission

\begin{tabular}{|c|c|}
\hline \multicolumn{2}{|c|}{ Blood Cell Counts } \\
\hline WBC & $6660 / \mu \mathrm{L}$ \\
\hline RBC & $37 \mathrm{I} \times 10^{4} / \mu \mathrm{L}$ \\
\hline $\mathrm{Hb}$ & $11.3 \mathrm{~g} / \mathrm{dL}$ \\
\hline $\mathrm{Ht}$ & $35.9 \%$ \\
\hline Plt & $18.6 \times 10^{4} / \mu \mathrm{L}$ \\
\hline \multicolumn{2}{|c|}{ Laboratory data } \\
\hline Total protein & $6.2 \mathrm{~g} / \mathrm{dL}$ \\
\hline Albumin & $3.3 \mathrm{mg} / \mathrm{dL}$ \\
\hline AST & $32 \mathrm{IU} / \mathrm{I}$ \\
\hline ALT & $31 \mathrm{IU} / \mathrm{I}$ \\
\hline $\mathrm{LDH}$ & $264 \mathrm{IU} / \mathrm{I}$ \\
\hline$\gamma$-GTP & $93 \mathrm{U} / \mathrm{I}$ \\
\hline BUN & $16.1 \mathrm{mg} / \mathrm{dL}$ \\
\hline Creatinine & $0.6 \mathrm{mg} / \mathrm{dL}$ \\
\hline $\mathrm{Na}$ & 144 mEq/L \\
\hline K & $3.9 \mathrm{mEq} / \mathrm{L}$ \\
\hline $\mathrm{Cl}$ & $107 \mathrm{mEq} / \mathrm{L}$ \\
\hline $\mathrm{Ca}$ & $3.34 \mathrm{mEq} / \mathrm{L}$ \\
\hline$P$ & $2.4 \mathrm{mEq} / \mathrm{L}$ \\
\hline UA & $6.7 \mathrm{mg} / \mathrm{dL}$ \\
\hline Lactate & $3.4 \mathrm{mmol} / \mathrm{l}$ \\
\hline Pyruvate & $1.37 \mathrm{mg} / \mathrm{dL}$ \\
\hline Triglyceride & $45 \mathrm{mg} / \mathrm{dL}$ \\
\hline HDL-C & $33 \mathrm{mg} / \mathrm{dL}$ \\
\hline LDL-C & $63 \mathrm{mg} / \mathrm{dL}$ \\
\hline Glucose & $73 \mathrm{mg} / \mathrm{dL}$ \\
\hline $\mathrm{HbA}_{\mathrm{Ic}}$ & $6.7 \%$ \\
\hline BNP & $1 / 30 \mathrm{pg} / \mathrm{mL}$ \\
\hline \multicolumn{2}{|c|}{ Arterial blood gas room air } \\
\hline $\mathrm{pH}$ & 7.379 \\
\hline $\mathrm{pCO}_{2}$ & $30.8 \mathrm{mmHg}$ \\
\hline $\mathrm{pO}_{2}$ & $78.3 \mathrm{mmHg}$ \\
\hline $\mathrm{HCO}_{3}$ & $17.8 \mathrm{mmol} / \mathrm{L}$ \\
\hline $\mathrm{BE}$ & $-5.9 \mathrm{mmol} / \mathrm{L}$ \\
\hline Lactate & $3.4 \mathrm{mmol} / \mathrm{L}$ \\
\hline Anion gap & $11.1 \mathrm{mmol} / \mathrm{L}$ \\
\hline
\end{tabular}

with amelioration of the transthoracic echocardiographic findings (Figure 3C) and a reduction in serum brain natriuretic peptide levels. The E/A value and deceleration time of E were improved to 1.2 and $190 \mathrm{msec}$, and the patient was discharged 4 weeks after hospital admission.

\section{Discussion}

Previous investigations have identified a number of mitochondrial DNA mutations causing human disease. ${ }^{2}$ Among these, an $\mathrm{A} \rightarrow \mathrm{G}$ transition at nucleotide 3243 (A3243G) of the tRNALeu (UUR) gene is common. Clinically, this mitochondrial DNA mutation has been shown to cause a unique syndrome called MELAS, which consists of mitochondrial myopathy, encephalopathy, lactic acidosis, and stroke-like episodes. The present patient carried

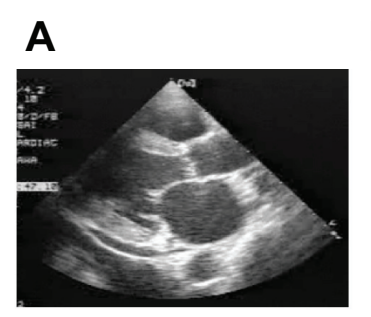

B

C

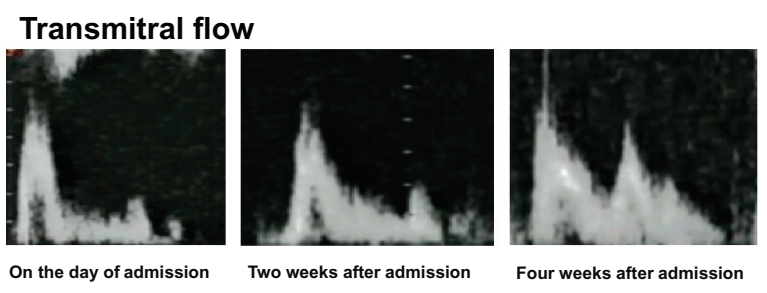

Figure 3 Transthoracic echocardiogram. Parasternal long-axis (A) and short-axis views (B) at end-diastolic phase show slight dilation of the left ventricle and left atrium. (C) Mitral pulsed Doppler flow at admission (left panel), 4 weeks after admission (middle panel), and 8 weeks after admission (right panel).

Notes: Early E and atrial A transmitral maximal flow velocity, and the deceleration time of $E$ were evaluated. At admission, the E/A value and the deceleration time of $E$ were 3.4 and $125 \mathrm{msec}$, respectively (left panel). At 4 weeks after admission, the E/A value and deceleration time of $E$ were 2.0 and $155 \mathrm{msec}$, respectively (middle panel). At 8 weeks after admission, the E/A value and deceleration time of E were 1.2 and $190 \mathrm{msec}$, respectively (right panel).

the A3242G mutation, but showed no disturbance in central nervous system functioning. Indeed, it has recently been shown that patients with this gene mutation show considerable variety in their clinical presentation.

Mitochondria play a pivotal role in cell metabolism, being the major site of ATP production via oxidative phosphorylation. Organs with high-energy expenditure

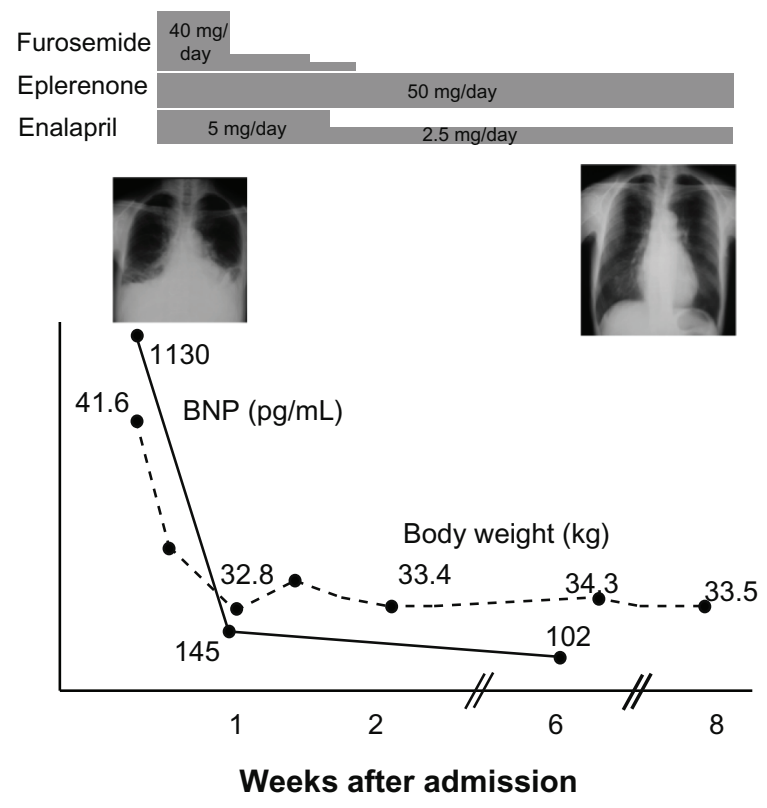

Figure 4 Clinical course. 
such as the brain, muscle, and heart, are vulnerable to the effects of mitochondrial DNA mutations. Indeed, mitochondrial cardiomyopathy is an important prognostic factor for mitochondrial disease. Previous reports have indicated that the clinical features of mitochondrial cardiomyopathy in patients carrying the $\mathrm{A} 3243 \mathrm{G}$ mutation show substantial variability. Hiruta et al described a patient with the A3243G mutation who presented with hypertrophic cardiomyopathy, ${ }^{3}$ whereas Momiyama et al reported on a patient with the same mutation who had dilated hypertrophic cardiomyopathy. ${ }^{4}$

The present case showed right-sided heart failure with a restrictive left ventricular filling pattern, which was effectively treated with furosemide, enalapril, and eplerenone. Recently, a similar case involving restrictive left ventricular filling was reported by Thebault et al. ${ }^{5}$ Dilatation of the left ventricle is composed of active relaxation and passive filling. Because active relaxation of the left ventricle during diastole is a process associated with high energy consumption, it is probable that mutation of mitochondrial DNA caused the diastolic dysfunction. As shown in Figure 4, medical treatment improved the symptoms successfully and was associated with amelioration of left ventricular filling. However, the long-term prognosis of the patient remains unknown. At the present time, there is no therapeutic strategy for definitive treatment of mitochondrial diseases, so careful follow-up of this patient is necessary.

The relationship between the mitochondrial gene mutation and the clinical characteristics of mitochondrial cardiomyopathy remains obscure. It is well known that normal and mutant mitochondrial DNA can coexist within the same cell (heteroplasmy). The degree of mutant heteroplasmy may be a factor involved in determination of the clinical phenotype. Quantitative analysis of mutated mitochondrial DNA and evaluation of the degree of heteroplasmy may provide clues to understanding the pathophysiology of mitochondrial cardiomyopathy.
In the present case, the electrocardiogram showed left ventricular hypertrophy with a strain pattern; however, left ventricular wall thickness was $10 \mathrm{~mm}$ and left ventricular hypertrophy was not observed. The precise mechanism of this discrepancy remains to be clarified. One possibility is that regression of left ventricular hypertrophy might occur during the long-term clinical course. Unfortunately, there is no record of a previous echocardiogram in the present case. Another possibility is that myocardial fibrosis might affect the findings on echocardiography. Histological evaluation could help our understanding of the mechanisms involved, but an endomyocardial biopsy was rejected by the patient.

Here we report the case of a diabetic Japanese woman with a mitochondrial A3243G mutation presenting with right-sided heart failure and a restrictive left ventricular filling pattern. This case highlights the substantial variability in clinical features of mitochondrial cardiomyopathy.

\section{Disclosure}

The authors report no conflicts of interest in this work.

\section{References}

1. Sproule DM, Kaufmann P. Mitochondrial encephalopathy, lactic acidosis, and strokelike episodes: basic concepts, clinical phenotype, and therapeutic management of MELAS syndrome. Ann N Y Acad Sci. 2008;1142:133-158.

2. Di Donato S. Multisystem manifestations of mitochondrial disorders. J Neurol. 2009;256:693-710.

3. Hiruta Y, Chin K, Shitomi K, et al. Mitochondrial encephalomyopathy with A to $G$ transition of mitochondrial transfer RNA(Leu(UUR)) 3,243 presenting hypertrophic cardiomyopathy. Intern Med. 1995;34: 670-673.

4. Momiyama Y, Atsumi Y, Ohsuzu F, et al. Rapid progression of cardiomyopathy in mitochondrial diabetes. Jpn Circ J. 1999;63: 130-132.

5. Thebault C, Ollivier R, Leurent G, Marcorelles P, Langella B, Donal E. Mitochondriopathy: a rare aetiology of restrictive cardiomyopathy. Eur J Echocardiogr. 2008;9:840-845.
International Medical Case Reports Journal

\section{Publish your work in this journal}

The International Medical Case Reports Journal is an international, peer-reviewed open-access journal publishing original case reports from all medical specialties. Previously unpublished medical posters are also accepted relating to any area of clinical or preclinical science. Submissions should not normally exceed 2,000 words or

\section{Dovepress}

4 published pages including figures, diagrams and references. The manuscript management system is completely online and includes a very quick and fair peer-review system, which is all easy to use. Visit http://www.dovepress.com/testimonials.php to read real quotes from published authors. 